\title{
El normalismo rural mexicano y la "conjura comunista" de los años sesenta. La experiencia estudiantil de Cañada Honda, Aguascalientes
}

\author{
Mexican Rural Normalism and the 1970s- \\ "Communist Conspiracy": The Student Experience \\ of Cañada Honda, Aguascalientes
}

\section{Sergio Ortiz Briano}

Escuela Normal Rural "Justo Sierra Méndez",

Cañada Honda, Aguascalientes.

sortiz_50@hotmail.com

\section{Salvador Camacho Sandoval}

Universidad Autónoma de Aguascalientes

camacho_sal@yahoo.com.mx

\section{Resumen}

La historia del normalismo rural mexicano suele asociarse a una historia de lucha y protesta en contra del gobierno; pero el movimiento estudiantil no ha sido homogéneo. Una de las mayores escisiones que ha tenido el normalismo rural mexicano ocurrió en 1959, no obstante, cinco años después, en la Escuela Normal Rural "Justo Sierra Méndez", de Cañada Honda, Aguascalientes, estudiantes normalistas se reunieron en el Congreso de la Unidad del Normalismo Rural para fortalecer su presencia política y social en todo el país y lograr que se les atendieran sus demandas particulares. El propósito de este artículo es analizar la dinámica que se generó entre estudiantes normalistas y autoridades durante los primeros años de la década de los sesenta, identificando, por un lado, las estrategias usadas por el estudiantado que buscaba hacerse visible y que sus demandas fueran atendidas y, por otro lado, las medidas que tomaron las autoridades gubernamentales para atemperar el protagonismo estudiantil. Esta confrontación era parte de las movilizaciones obreras y magisteriales en contra de un gobierno que usaba la fuerza y el discurso anticomunista para anular toda expresión de inconformidad y oposición ciudadana.

Palabras clave: Normalismo rural mexicano, movimiento estudiantil, conflicto social. 


\section{Abstract}

The history of the Mexican rural teacher training colleges has been usually associated to a history of political struggles and protests against the government, but the student movement has not been homogeneous. One of the key splits in the rural teacher training colleges occurred in 1959; nevertheless five years later, in the college Justo Sierra Méndez in Cañada Honda, Aguascalientes, teacher trainees met at the United Rural Teacher Training College Congress with the purpose of strengthening their presence across the country. The aim of this article is to analyze the dynamics between teacher trainees and the Mexican authorities during the first half of the 1970s. We shed light, on the one hand, on the strategies used by the students seeking to make themselves visible and achieve their demands; on the other, on the measures taken by the government to temper the students' prominence. This confrontation was part of the worker and teacher movements against a government that used force and an anti-communist narrative to suppress inconformity and opposition from the citizenry.

Keywords: Mexican rural teachers, student movement, social conflict.

\section{Introducción}

Los antecedentes del normalismo rural en México los encontramos en el Porfiriato (18761911) y en la segunda década del siglo xx; sin embargo, no fue sino hasta los años treinta, durante el gobierno de Lázaro Cárdenas (1934-1940), que luego de su reconocimiento como Regionales Campesinas las normales rurales llegaron a convertirse en elemento sincrético de la Revolución mexicana y pieza importante en la creación de un sistema educativo tendente a apoyar la reconstrucción del Estado mexicano, el fortalecimiento del nacionalismo y la creación de una cultura moderna en una población casi analfabeta y con serios problemas sociales y económicos. ${ }^{1}$

En los años treinta llegaron a existir 35 escuelas normales rurales en el país y en 2017 sobreviven sólo 16 cuyo alumnado está agrupado en la Federación de Estudiantes Campesinos Socialistas de México (FECSM), con excepción de la escuela de San José de las Flores, en Tamaulipas. A pesar de que históricamente estas escuelas se han mantenido en una demanda constante por la mejora de las condiciones de vida de los internados, no es sino en momentos de conflicto cuando las miradas se vuelven hacia ellas y se visibilizan. Así sucedió nuevamente a raíz de la desaparición de los 43 estudiantes de la Escuela Normal Rural "Raúl Isidro Burgos"

${ }^{1}$ Sobre la educación posrevolucionaria se ha escrito mucho. Un referente importante es Vaughan (2000). Sobre el normalismo rural véase Civera, 2013. 
de Ayotzinapa, Guerrero, en la noche del 26 de septiembre de 2014. A partir de estos hechos ominosos y de la reforma educativa, que exige cumplimiento de nuevas reglas para evaluar y promover a los profesores, se ha puesto en la mesa de discusión la participación social y política de los jóvenes normalistas y la pertinencia de apoyar o no a las normales rurales.

Desde la desaparición de los normalistas, los padres de familia y diversas organizaciones sociales no han dejado de exigir que se esclarezca el crimen y se dé con el paradero de los estudiantes, pero las autoridades gubernamentales no han cumplido porque son jueces y parte de la tragedia. Se ha transitado de las declaraciones de una "verdad histórica"2 hasta el anuncio de un "tercer estudio" en el que, además de la participación de especialistas internacionales, se contó con un perito del Grupo Interdisciplinario de Expertos Independientes (GIEI) que luego terminó en el descrédito. ${ }^{3}$ Las investigaciones no han ofrecido resultados convincentes pero sí han sacado a la luz pública la descomposición de la vida política del país y las incapacidades y vicios gubernamentales; muestra de ello es la corrupción de autoridades de los tres niveles de gobierno y sus vínculos con el narcotráfico. Aunque el asunto es más complejo e involucra al Estado mexicano, "estamos hablando de una alianza non sancta, de un entendimiento que tiene como base la corrupción pero que va más allá de eso: en el fondo lo que hemos visto en el siglo xx en México [...] es un matrimonio por conveniencia entre el narco y el Estado" (Chabat, 2005).

Los sucesos ocurridos en Iguala, Guerrero, impactaron a la sociedad mexicana y de manera especial a las normales rurales del país. La vida cotidiana de los estudiantes de estas instituciones se alteró de manera significativa, en particular en la Escuela Normal Rural de Cañada Honda, Aguascalientes, ${ }^{4}$ donde se reunieron los líderes estudiantiles de las escuelas normales rurales del país. ${ }^{5}$ El estudiantado de esta escuela está compuesto por mujeres y por ello tiene características muy especiales; según Evangelina Terán su participación política inició en la década de los años cuarenta cuando se insertaron en un movimiento nacional de huelga. A partir de entonces las jóvenes normalistas han realizado acciones políticas dentro de la esfera

\footnotetext{
2 Jesús Murillo Karam, procurador general de la República, señaló que los 43 normalistas fueron asesinados y sus cadáveres incinerados en el basurero municipal de Cocula: "Esa es la verdad histórica de los hechos", concluyó (CastiIlo, 2015).

3 "GIEl: poner fin al descrédito", La Jornada, 6 de febrero de 2016

${ }^{4}$ Esta escuela tuvo su origen en el Soconusco, Chiapas, en 1937 y dos años después se estableció en Cañada Honda. Cuenta con dos edificios: el que alberga el área académica, construido a principios de la década de los años setenta del siglo xx, y el Edificio Central que fue construido "todo de mampostería", además del casco de una hacienda del Porfiriato. Archivo General de la Escuela Normal Rural "Justo Sierra Méndez" (ACENRJSM), Caja 30, 1960-1964, "Se remite información y croquis relacionados con las propiedades de esta escuela", Cañada Honda, Aguascalientes a 17 de febrero de 1964.

${ }^{5}$ Las actividades que realiza el estudiantado se clasifican en cinco ejes: político, académico, cultural, deportivo y de módulos de producción. "Ejes Principales", Orígenes de la fECSM. Periódico Mural de la Sociedad de Alumnas "Amina Madera Lauterio", Escuela Normal Rural de Cañada Honda, Ags., 2009.
} 
del normalismo rural y de otros movimientos sociales. El tema de la reivindicación de las mujeres también ha sido muy importante (Terán, 2009).

Una vez más la Normal de Cañada Honda se convirtió en sede de la FECSM, organismo que, no obstante las concomitancias y rupturas a lo largo de su historia, sigue representando la fraternidad y la lucha de los normalistas. Fue una reunión extraordinaria cuyo objetivo era "discutir las formas de participación de cada una de estas escuelas en torno a la conmemoración del Primer Aniversario de los acontecimientos de Iguala". ${ }^{6}$ Aunque resultó difícil conocer las discusiones y acuerdos, no fue un secreto que en este congreso se definieron formas de manifestación y reclamo frente a las agresiones de la que ha sido objeto el normalismo rural mexicano?

El contexto social y político del normalismo rural es complejo y enturbia aún más la vida de estas escuelas y su relación con el gobierno. Semejante a lo que ha sucedido a lo largo de su historia, estas escuelas continúan funcionando bajo el sistema de internado y su sostenimiento es responsabilidad del Estado, pero siguen con carencias y con la consecuente inconformidad estudiantil. Recordemos que ya desde los años treinta del siglo pasado los estudiantes salieron a las calles como condición para ser escuchados por parte de las autoridades. En la mayoría de los casos las respuestas oficiales acaban siendo promesas que al no cumplirse vuelven a ser motivo de nuevas manifestaciones.

Uno de los casos más recientes, en cuanto a promesas incumplidas, ocurrió a finales de 2014 cuando, a raíz de los acontecimientos de septiembre 26-27, se anunció que se asignarían 400 millones de pesos para la "redignificación" de las 15 normales rurales; sin embargo, no sólo no se concretó la promesa, sino que se redujo el monto de 400 millones a \$149813563.00 y sólo se benefició a seis escuelas. Pero, además, en una decisión que resulta difícil comprender la normal rural "Raúl Isidro Burgos" fue excluida de este apoyo, a pesar de que el ofrecimiento se desprendió a partir de los asesinatos y la desaparición forzada de los 43 normalistas de esta escuela. ${ }^{8}$ Esta circunstancia ha renovado el temor entre los normalistas rurales, toda vez

\footnotetext{
${ }^{6}$ Las actividades realizadas se dieron del 7 al 11 de septiembre de 2015. Entrevista de Sergio Ortiz Briano a Z, 2 de septiembre de 2015

7 Referirse al normalismo rural mexicano implica incursionar en el análisis de los movimientos estudiantiles para lo cual existe ya literatura en América Latina, tal como lo dejan ver los trabajos de Renate Marsiske y Álvaro Acevedo, citados en la bibliografía. También vale señalar que las publicaciones sobre los estudiantes normalistas se dan generalmente a partir de acontecimientos críticos y violentos, y se distinguen de los movimientos estudiantiles universitarios.

${ }^{8}$ En "Lic. Jesús Orta Martínez. Director General" SEP, Oficialía Mayor, Dirección General de Presupuestos y Recursos Financieros México, D. F., 14 de septiembre de 2015 y Dirección General de Educación Superior para Profesionales de la Educación en respuesta a solicitud presentada al Instituto Nacional de Transparencia y Acceso a la Información con Folio 0001100423015, 28 de septiembre de 2015 y DGESPE en respuesta al Recurso de Revisión Expediente rda 5249/15 de fecha 12 de octubre de 2015, respectivamente.
} 
que la respuesta de la autoridad ha sido la amenaza y el arresto de normalistas en cárceles de alta seguridad, acusándolos de delitos federales. ${ }^{9}$

Lo ocurrido recuerda la realización del Congreso de la Unidad del Normalismo Rural desarrollado en noviembre de 1964 en Cañada Honda, Aguascalientes. La historia se repite. El propósito del presente trabajo es lograr un acercamiento a la dinámica generada entre estudiantes normalistas y autoridades al inicio de los años sesenta para conocer las estrategias empleadas por el estudiantado para hacerse visible y el protagonismo de esta escuela normal frente a un gobierno que asumió el discurso "anticomunista" y culminó con el cierre de 14 de las 29 normales rurales. Esta experiencia ayuda a explicar parte del origen de los temores acumulados por el estudiantado en los años posteriores.

El presente trabajo se organiza en cuatro partes, la primera es una exposición de los antecedentes, en la segunda se describe brevemente el contexto político del momento, lo cual ayuda a identificar las medidas implementadas por las autoridades para enfrentar las inquietudes y demandas de los estudiantes; en la tercera parte se mencionan algunas características que definen a este tipo de escuelas y se describe el activismo político del normalismo rural, mismo que consigue llevar a cabo el "Congreso de la Unidad", en noviembre de 1964; y, finalmente, en la cuarta parte se describen algunos casos en los que la prensa, sirviendo a los intereses gubernamentales, se convirtió en un agente más que alimentó el hostigamiento al normalismo rural mexicano.

\section{Antecedentes de ubicación: ¿cardenistas "de hueso colorado"?}

En 1933 se crearon las escuelas regionales campesinas ${ }^{10}$ y fue durante el gobierno de Lázaro Cárdenas que los estudiantes se vieron influenciados por la política de "llevar adelante los postulados de la Revolución [y la idea de] que los obreros, campesinos y las masas popula-

\footnotetext{
${ }^{9}$ Los casos son diversos. A manera de ejemplo está lo ocurrido con estudiantes normalistas de Michoacán, que luego de ser acusados por presuntas violaciones a la Ley Federal de Armas de Fuego y Explosivos fueron detenidos 52 estudiantes (22 mujeres y 30 hombres) el 7 de diciembre de 2015. Efemex, 9 de diciembre de 2015. En Aguascalientes el 9 de junio de 2017 estudiantes normalistas fueron arrestados y golpeados por la policía municipal. La jornada Aguascalientes, 10 de junio de 2017

${ }^{10}$ Las escuelas regionales campesinas "son escuelas mixtas y funcionan como internados, estando a cargo del Gobierno Federal la alimentación y el vestuario". Surgieron con el Plan Sexenal de 1934 para rescatar del abandono en que se encontraban las escuelas centrales agrícolas -que eran instituciones de fomento agrícola y agencias de crédito rural- y amalgamarlas con las normales rurales existentes. Su principal objeto consistía "en fijar los principios básicos y los procedimientos de la explotación racional de la tierra" (Poder Ejecutivo Federal, 1941: 21 y 116).
} 
res prosperan en agrupamiento de sus fuerzas". ${ }^{11}$ Dos años después se realizó el Congreso Constituyente de la FECSM y se sentaron las bases para transitar de una escuela del Estado posrevolucionario del cardenismo ${ }^{12}$ a una escuela normal rural alejada y de resistencias al propio gobierno.

Aun cuando durante el gobierno de Lázaro Cárdenas este sistema de formación de maestros tuvo un impulso importante, las condiciones de pobreza de las Regionales Campesinas no lograron abatirse como se esperaba, por lo que ya desde esos años los estudiantes demandaron a las autoridades de manera enérgica la atención a sus necesidades, llegando a cuestionar al propio presidente de la República arguyendo una falta de compromiso con la clase desheredada. ${ }^{13}$

Las demandas estudiantiles iban desde la solución a sus necesidades relacionadas con la beca alimenticia, recreación escolar, uniformes, materiales para talleres y equipo de dormitorio, hasta la destitución de docentes y directores que, desde su opinión, carecían de formación para el buen desempeño de sus responsabilidades. A veces los directivos de las escuelas solicitaban apoyos a la SEP, pero finalmente era con la intervención del estudiantado como se lograba que las autoridades respondieran. Durante los años treinta la relación con el gobierno estuvo basada en un juego epistolar, pues los estudiantes manifestaban posturas de exigencia en sus peticiones mediante cartas y oficios, y las autoridades respondían de la misma forma con la promesa de atender sus demandas.

A finales del cardenismo el lenguaje formal y respetuoso del estudiantado se fue transformando a uno mucho más exigente. Del 20 al 30 de abril de 1939 los estudiantes tuvieron su congreso ordinario en El Mexe, Hidalgo, y plantearon la urgente "necesidad de elevar el nivel de vida de las normales rurales". ${ }^{14}$ A partir de 1940 empezaron a manifestarse en distintas

${ }^{11}$ Discurso pronunciado por un estudiante en el Tercer Congreso de Estudiantes Campesinos de la FECSM, 20 de noviembre de 1937. Surco. Quincenal de Información y Doctrina, Morelia, Michoacán, núm. 12, 508-005-C-MORELIA, Universidad Michoacana, Hemeroteca Pública Universitaria, p. 4.

${ }^{12}$ Al referirnos al cardenismo queremos aludir a la corriente ideológica "inaugurada" por Lázaro Cárdenas durante su mandato como presidente de México, de 1934 a 1940. El cardenismo impulsó el reparto de tierras, la nacionalización del petróleo, la unificación del movimiento obrero y campesino, y la educación rural. La formación de maestros rurales fue una prioridad al querer "fundar y desarrollar en las conciencias el concepto de la preeminencia de los intereses de la colectividad sobre los intereses privados o individuales" (Poder Ejecutivo Federal, 1941: 459)

${ }^{13}$ En oficio dirigido al jefe del Departamento de Enseñanza Agrícola y Normal Rural, además de manifestar sus dudas acerca del compromiso del general Cárdenas para con la clase desheredada, le expresaban lo siguiente: "definitivamente (queremos que) nos diga si en el presente año no habrá resoluciones favorables, pues en oficios anteriores nos ha dicho que ya se procede a solucionar esa situación, pero hasta la fecha nada de real se ha visto, [por lo que] esperamos se nos conteste lo más pronto posible porque la situación es apremiante y necesitamos saber a qué atenernos", AHSEP, fondo SEP, sección DEANR 1937-1938, Guanajuato, c. 6, Exp. X/100(X-5-B)(724.4), 1938, Pedimos se atienda a las Regionales Campesinas de Jalpa de Méndez, Tab.; Vanguardia, Oax., y Huetamo, Mich., 4 de octubre de 1938.

14 Temario del Congreso Ordinario de la FECSM, en "Historial de la FECSM. COPIN-AYOTZINAPA 05-06", en Federación de Estudiantes Campesinos Socialistas de México, 2005-2006: 7 
normales y, finalmente, estalló una huelga general en julio de ese año. ${ }^{15}$ Los resultados fueron parciales, pero a partir de esta huelga, que fue la primera de carácter nacional, los estudiantes descubrieron la fuerza de su organización.

\section{Sin banderas de agitación ni intromisiones}

Para la década de los años cincuenta la situación de las normales rurales no había mejorado; en todo caso, se conjugaron otros acontecimientos que afectaron la dinámica de las normales y de la FECSM. A partir de 1956 inició un conflicto magisterial en el Distrito Federal16 y otros más con los ferrocarrileros y electricistas, los cuales impactaron de alguna manera en la organización de los normalistas rurales.

La radicalidad de las demandas presentadas por las sociedades de alumnos fue motivo de preocupación tanto para las autoridades gubernamentales como para la dirigencia del Sindicato Nacional de Trabajadores de la Educación (SNTE). En 1958 los normalistas estuvieron atentos al movimiento magisterial de Othón Salazar y trabajaron desde sus organismos de representación nacional hasta las comunidades estudiantiles de todas y cada una de estas escuelas. La FECSM apoyó los paros de actividades como respuesta a "la pasividad e indiferencia de las autoridades de Educación hacia los problemas que confrontan los estudiantes de las Escuelas Normales Rurales del país". ${ }^{17}$ Con esta presión los normalistas lograron respuestas favorables; sin embargo, la buena disposición para atender estas demandas ${ }^{18}$ se observaba como estrategia para llevar al estudiantado a transitar de una autonomía tantas veces defendida por los estudiantes a una "autonomía asistida" por la dirigencia sindical.

De acuerdo con J. Refugio Esparza Reyes, representante sindical de la Especialidad del SNTE, "para sacar al Sistema de la más dura de sus crisis" y consciente de las causas que

${ }^{15}$ Esta experiencia ha sido definida por los estudiantes como la más importante del periodo de vida de la FECSM. Idem.

${ }^{16}$ En 1956 los maestros de primaria del Distrito Federal, integrantes de la Sección IX, se movilizaron en contra de la dirigencia nacional del SNTE: cuestionaron su autoridad y legitimidad luego de que aceptó del gobierno un incremento salarial muy por debajo de lo que se había solicitado (14\% en lugar de 30\%). Otro móvil fue la exigencia para que se desarrollaran elecciones democráticas en las secciones del SNTE. "El SNTE no sabe de la huelga", El Sol del Centro, 19 de abril de 1956; ACENRJSM, Caja 28, 1954-1957, SNTE, "Se hacen observaciones por la actitud que se indica", 5 y 9 de febrero de 1959; Cardiel, 1982: 327-359.

${ }^{17}$ Rodolfo Tamayo Martínez, "Informe de la semana de guardia del 28 de abril al 04 de mayo", ACENRJsM, Caja 29, 1957-1961, 5 de mayo de 1958.

${ }_{18}$ Un ejemplo de la "buena disposición" de las autoridades se dio con la "exigencia" de los estudiantes para que se dotara de camiones de carga y de pasajeros a todas las escuelas. La respuesta fue la siguiente: "A todas las Escuelas Normales se les ha dotado de camiones, excepto Misantla, Ver., Huamantla, Tlax. y Xochiapulco, Pue., para quienes ya se gestiona la compra de dichos camiones", Rodolfo Tamayo Martínez, "Informe de la semana de guardia del 28 de abril al 04 de mayo", AGENRJSM, Caja 29, 1957-1961, 5 de mayo de 1958. En este sentido, para el caso de Misantla, Ver., el camión en cuestión le fue entregado el 21 de septiembre de 1960. AGENRJSM, Caja 29, 1957-1961, SEP, DGEN, "El día de ayer fue entregado el camión al Director de Misantla, Ver.", 22 de septiembre de 1960. 
originaban los conflictos al interior de las normales rurales, había que disminuir las prebendas de las que gozaban los maestros y los dirigentes de la FECSM. Una medida era, a decir del propio Esparza Reyes, "quitarles a los alumnos sus banderas de agitación [...] y evitar agitaciones estériles e intromisiones de los empleados y maestros en los problemas estudiantiles" 19 Por ello, la dirigencia sindical dejaba sin efecto una disposición de la Dirección General de Enseñanza Normal que amparaba a muchos ex dirigentes de la FECSM que por no contar aún con plaza se encontraban comisionados en "varias escuelas anexas a las Normales Rurales". También pedía que los jóvenes fueran retirados de estas escuelas debido a que seguían actuando como dirigentes estudiantiles. Para el maestro Esparza Reyes este hecho era "una forma inmoral de pervertir a la juventud y de transformar en botín la dirección nacional de una organización de trayectoria revolucionaria”, ${ }^{20}$ como lo era para ellos la FECSM.

Estas críticas a los líderes de la organización estudiantil se daban en el marco de una lucha en contra de la izquierda mexicana, para lo cual el SNTE, el gobierno y su partido, empresarios, representantes de la Iglesia y grupos conservadores abanderaron el discurso anticomunista que promovía el gobierno estadounidense en el contexto de la Guerra Fría (Pellicer y Reyna, 1978). Fue así que para conjurar la oposición que involucraba el fantasma del comunismo, una de las estrategias del Estado mexicano era asumir el discurso de la "familia revolucionaria" entre obreros y trabajadores del gobierno, incluyendo a los futuros maestros, por lo que no se podía permitir la intromisión de ningún otro partido político o ideología que pusieran en riesgo la "unidad" y que no estuvieran bajo el control del aparato estatal y en particular de la Confederación de Trabajadores de México (СTM) (Glockner, 2007: 85-103).

Para poder controlar a un amplio sector de la población, la CTM creó a su vez la Confederación de Jóvenes Mexicanos (CJM), que logró influir en el Congreso de la FECSM realizado en la Normal Rural de Tamatán, Tamaulipas, para colocar a Liberato Montenegro como secretario general de dicha organización durante 1958 y los primeros meses de 1959 y quien luego se convertiría en el dirigente nacional de la CJM (Aguayo, 2002: 195-197). Así la confederación influyó, por un tiempo, en las decisiones que tomaba la FECSM. ${ }^{21}$

Al final de la década se dio una ruptura entre las autoridades y el estudiantado. Los mismos mecanismos de control y negociación construidos entre ambos actores se convirtieron en el argumento de las autoridades para cuestionar y desarticular a la organización estudiantil, como si se tratara de mecanismos creados y establecidos unilateralmente por los estudiantes. Todo comenzó en el XVI Congreso realizado en Cañada Honda, Aguasca-

\footnotetext{
${ }^{19}$ ACENRJSM, Caja 28, 1954-1957, "Informe del Representante Sindical de la Especialidad del 15 de marzo de 1956 al 19 de febrero de 1959", Segunda Asamblea Nacional, México, D. F., 19 de febrero de 1959. Refugio Esparza Reyes fue gobernador de Aguascalientes de 1974 a 1980.

${ }^{20}$ ACENRJSM, Caja 28, 1954-1957, "Informe del Representante Sindical de la Especialidad del 15 de marzo de 1956 al 19 de febrero de 1959", Segunda Asamblea Nacional, México, D. F., 19 de febrero de 1959.

${ }^{21}$ Entrevista de Sergio Ortiz Briano a Ruperto Ortiz Gámez, Nieves, Zac., 19 de septiembre de 2008.
} 
lientes, en donde se nombró el nuevo comité de la FECSM para el año 1960.22 Liberato Montenegro pretendió marcar una tendencia que provocó división en la organización estudiantil (Aguayo, 2002: 195-197); una primera inconformidad era que "no se había desarrollado el Congreso con democracia", ${ }^{23}$ pero no tuvo eco en las delegaciones que apoyaban a Montenegro. De esta manera las normales rurales quedaron divididas e integradas en dos corrientes: por un lado, las sociedades de alumnos que decían pertenecer a la FECSM y respaldaban a Montenegro y, por otro, 11 sociedades de alumnos que se autodefinieron como Consejo Nacional Permanente, identificadas más adelante como Consejo Nacional de Estudiantes Campesinos Socialistas de México (CNECSM).

Durante esos años al interior del normalismo rural se podían identificar dos características, la injerencia de la representación sindical del magisterio, que se expresa como operador de la preocupación de las autoridades frente a las manifestaciones estudiantiles, y la decisión de la СтM de controlar a través de las decisiones de la FECSM a los grupos normalistas e incorporarlos a la "familia revolucionaria".

\section{Unidos aun en la división}

Para el normalismo mexicano tuvieron impacto los movimientos sociales que se vivieron durante los gobiernos de Adolfo López Mateos (1958-1964) y Gustavo Díaz Ordaz (19641970). Además, el triunfo de la Revolución cubana, en 1959, influyó de manera notoria ideológica y políticamente en los movimientos de obreros, campesinos y estudiantes que luchaban en contra del gobierno debido a las pésimas condiciones de trabajo, las carencias en las escuelas y también por el autoritarismo existente. Pero en medio de la Guerra Fría y una campaña anticomunista en México grupos de la población no tuvieron mayores simpatías por estos grupos disidentes. La Guerra Fría fue un enfrentamiento político e ideológico expresado en una guerra de palabras tendentes a influir en la opinión pública, para lo cual los medios y el mundo de la cultura eran muy importantes. Como dice Elisa Servín, "[...] si algo compartieron entonces los gobiernos estadounidense y soviético con la Alemania nazi, fue el uso de las campañas de propaganda para influir en las percepciones y los comportamientos sociales, inflingiendo miedo, creando monstruos o héroes, o bien manipulando la información en aras de manejar a la opinión pública” (Servín, 2004: 10-11).

22 AGENRJSM, Caja 29, 1957-1961, DGEN Relativo al próximo Congreso de la FECSM, 12 y 31 de marzo de 1960. El Congreso se inició el 3 de abril con un desfile en la ciudad de Aguascalientes en el que participaron las delegaciones de estudiantes de las normales rurales. "Desfilaron por la ciudad los normalistas rurales", El Sol del Centro, 4 de abril de 1960. AHEA,

${ }^{23}$ Entrevista de Sergio Ortiz Briano a Ruperto Ortiz Gámez, Nieves, Zac., 19 de septiembre de 2008. 
La prensa se había encargado de promover el descrédito de los movimientos populares y avivaba el fantasma del comunismo. Cualquier grupo social organizado que exigía solución de problemas y respeto a los derechos laborales, de organización y de libertad de expresión era calificado de comunista y relacionado con lo que la prensa definía como "la conspiración roja internacional" encabezada por la uRss y Cuba (Meyer, 2004). En los hechos, con este discurso no se quería contener al comunismo, sino restarle influencia política y social a los partidarios del nacionalismo económico; las baterías se dirigieron no sólo contra el Partido Comunista Mexicano y algunos reconocidos marxistas, sino también en contra del ex presidente Lázaro Cárdenas y el dirigente obrero Vicente Lombardo Toledano, las figuras más representativas de la izquierda en la política oficial.

La participación del sector estudiantil en las manifestaciones de fines de los años cincuenta y principios de los sesenta empezó a tener un protagonismo importante (Daniel C. García, 2006: 77). No fue extraño que en las normales rural los estudiantes apoyaran las causas de obreros y campesinos en la lucha por la conquista de mejores condiciones de vida. Por consiguiente, estos estudiantes también sufrieron la persecución y el hostigamiento por parte del gobierno, que no ocultó su preocupación por la fuerza que representaba la intervención organizada de los normalistas. La confrontación se dio en varios momentos y puso a prueba la capacidad de organización estudiantil y su pericia para afrontar las vicisitudes que significaba oponerse al gobierno. Uno de los retos que debieron enfrentar los estudiantes fue la injerencia del gobierno a través de la infiltración de estudiantes identificados como "oficialistas" en las decisiones y la vida política de la FECSM. Mas a pesar de esta "infiltración" muchas actividades propias del normalismo rural continuaron realizándose de manera regular. Además, la unificación se dio finalmente en el XVII Congreso Nacional de la FECSM que se llevó a cabo del 8 al 13 de mayo de 1961 en La Huerta, Michoacán, ${ }^{24}$ al que asistieron representantes de todas las normales rurales. Lucio Cabañas, quien más tarde fuera líder guerrillero, supo negociar con el grupo de Liberato Montenegro y también con otros bandos, ${ }^{25}$ entre ellos el CNECSM, ${ }^{26}$ liderado por Antonio Valtierra Limones, estudiante de Salaices, Chihuahua. Con el propósito de unificar a los grupos Eusebio Mata Mejía, Eleno Medina Vázquez (del grupo cabañista) y Miguel Quiñónez Pedroza dieron seguimiento a las

${ }^{24}$ AGENRJSM, Caja 29, 1957-1961, DGEN, "Circular \# 23 y \#26", 26 de marzo y 3 de mayo de 1961.

${ }^{25}$ En el Congreso de El Mexe, Hidalgo, de 1962, Cabañas fue electo secretario general de la FECSM y en su interés de unificar a todas las escuelas decidió recorrer cada una de ellas, llegando a ser reconocido como dirigente único (Glockner, 2007: 85-103). "Para 1960 el liderazgo de Lucio ya era nacional" (Castellanos, 2008: 106).

${ }^{26}$ Este grupo cuya demanda era desconocer a la dirigencia de la CJM y la integración de un Comité de Unidad quedó integrado por las normales rurales de San Marcos, Zacatecas; Cañada Honda, Aguascalientes; Salaices y Saucillo, del estado de Chihuahua; Aguilera, Durango; Santa Teresa, Coahuila; Roque, Guanajuato; Palmira, Morelos; Panotla, Tlaxcala; Atequiza, Jalisco y El Quinto, Sonora. Entrevista de Sergio Ortiz Briano a Pedro Medina Calderón, 26 de diciembre de 2015 . 
demandas presentadas por las dos organizaciones estudiantiles en $1963 .{ }^{27}$ Este último estudiante poco tiempo después formó parte de los "Mártires de Madera".28

Una de las acciones del CNECSM fue pedir a la Dirección General de Educación Normal que se les permitiera intervenir en los procesos de selección e inscripción de alumnos para cuidar que se aceptaran exclusivamente hijos de campesinos. La respuesta de las autoridades fue la siguiente: "La aplicación de las pruebas de admisión a los jóvenes campesinos que soliciten ingresar a las Escuelas, es de la exclusiva competencia del Director y personal docente de las mismas. Sin embargo, ya giramos instrucciones a los C.C. Directores de las Escuelas para que los representantes del alumnado cooperen con el personal docente a fin de evitar la inscripción de jóvenes que no sean de procedencia netamente campesina. ${ }^{29}$

Ese mismo año de 1963 los normalistas rurales de ambas facciones exigieron unidos el cumplimiento de acuerdos por parte del gobierno para paliar, por lo menos, las condiciones paupérrimas en las que se encontraban los internados y las instalaciones escolares en general. Ambas representaciones estudiantiles exigían a las autoridades lo siguiente:

- La creación de 29 plazas de supervisores del servicio de alimentación.

- Establecimiento de mecanismos adecuados para adquirir los víveres en las condiciones comerciales de contado.

- Atender las denuncias que se presenten y cuidar que los fondos destinados a la alimentación se apliquen adecuadamente.

- Que al principiar los cursos se acepte por parte de las autoridades la presencia en las escuelas de un número de alumnos igual al de las becas autorizadas, más el cuatro por ciento.

- La creación del número de plazas necesarias para atender debidamente los servicios de cada escuela, según las exigencias de cada una de ellas.

- Incremento a la dotación diaria de medicinas por alumno.

- Realizar un estudio para ver en qué medida era suficiente o no la ración alimenticia de $\$ 4.75$ por alumno.

- Aumentar la Partida de Recreación Escolar de 5 a 8 pesos semanales.

${ }^{27}$ AGENRJSM, Caja 30, 1960-1964, SEP, Subsecretaría General, "Haciendo referencia a su oficio enviado con fecha 3 del presente mes y hago referencia a las conclusiones que constan en el acta de fecha 28 del presente", 19 y 28 de octubre de 1963.

${ }^{28}$ En la madrugada del 23 de septiembre de 1965 "el cuartel que alojaba en Madera a 120 soldados federales, fue asaltado por un grupo no precisado de jóvenes que al grito de ríndanse, los tenemos completamente rodeados, intentaron apoderarse del cuartel. El grupo asaltante lo formaban un médico y profesor normalista _Pablo Gómez Ramírez-y un ex maestro rural que sirvió en una escuela rural del estado de Chihuahua, Arturo Gámiz García, considerados los dos como los jefes del grupo" (Valdés, 1982: 202-343)

${ }^{29}$ Alfonso Sierra Partida, director general de Enseñanza Normal, ACEnRssm, Caja 30, 1960-1964, México, D.F., 16 de junio de 1964. 
- Dotar a cada una de las escuelas de un transporte escolar.

- La creación de 3000 becas en el sistema de escuelas normales rurales. ${ }^{30}$

Al no obtener respuesta los alumnos participaron activamente en paros de actividades académicas, movilizaciones y manifestaciones simultáneas en ciudades y plazas públicas dándole a este reclamo un impacto nacional. ${ }^{31}$ En este proceso sucedieron algunos hechos importantes que ayudan a comprender la relación de los estudiantes y el gobierno, generalmente sujeta a negociaciones coyunturales; por un lado, el respaldo de las sociedades de alumnos para el desarrollo de tareas propias del activismo político, como ocurrió con la intervención de la representación estudiantil de la similar de San Marcos, Zacatecas, cuando envió a un grupo de alumnos para que auxiliaran "a las compañeras [de Cañada Honda] en las guardias que se verificarían [...] con motivo del movimiento de los normalistas rurales" ${ }^{32}$ Por otro lado, los estudiantes supieron que ante la SEP tenían más presencia y poder de negociación que las autoridades de sus escuelas, por lo que crearon alianzas entre ellos, como sucedió en Cañada Honda donde las estudiantes le informaban al director de la escuela de cada una de las actividades que realizaban, aunque no siempre las relaciones fueron cordiales.

Fue un periodo de activismo intenso en donde la dirigencia nacional se organizó para llevar a cabo paros de actividades de manera simultánea en todas estas normales. Así, el 17 y el 18 de octubre de 1963 se llevó a cabo un paro de actividades "con motivo del movimiento de los normalistas rurales". ${ }^{33}$ Lo mismo sucedió el día 22 cuando el Comité de Lucha Estudiantil informó sobre la realización de un paro de 12 horas para ese día y dos días después, ante las negativas de la SEP de responder al pliego petitorio que se presentó el 3 de octubre. ${ }^{34}$

Finalmente, al comprender que sus manifestaciones no tenían la respuesta deseada por parte de la autoridad, los estudiantes se declararon en Huelga Nacional el 25 de octubre y sólo así consiguieron una respuesta positiva de las autoridades educativas, así como la firma

30 ACENRJSM, Caja 30, 1960-1964, "Pliego de peticiones", presentado ante la SEP, FECSM y CNECSM, 3 de octubre de 1963.

${ }^{31}$ ACENRJSM, Caja 30, 1960-1964, "Comunicando salida a Loreto", en el que informaban al director la salida de la Escuela "de 182 alumnas, incluyendo en ellas la Banda de Guerra al Pueblo de Loreto, Zac., con el objeto de realizar un mitin de carácter estudiantil". Documento firmado "Respetuosamente. Por la liberación de las juventudes explotadas; Por la resolución favorable de nuestros problemas; Por la Sociedad de Alumnas. El Comité de Lucha Estudiantil. Presidente Francisca Hernández G. y secretaria Francisca Villegas. Sociedad de Alumnas 'Amalia Solórzano de Cárdenas'", FECSM, CJM, FMJD, UIE, Cañada Honda, Ags., 27 de octubre de 1963.

32 AGENRJSM, Caja 30, 1960-1964, "Identificación", Sociedad de Alumnos "Lázaro Cárdenas", fECSM, CJM, UIE, FMJD, Secretaría General, San Marcos, Zacatecas, 17 de octubre de 1963.

33 ldem.

${ }^{34}$ ACENRJSM, Caja 30, 1960-1964, "Comunicando paro de 12 horas, Comunicando paro Nacional de las Escuelas Normales Rurales y Anunciando paro de Labores", 24 y 25 de octubre de 1963. En ese documento se informaba al director que la organización de la escuela quedaría "bajo la vigilancia del Comité de Lucha Estudiantil [aunque sólo lo hacían] de su conocimiento para que [tomara] debida nota de ello". Sociedad de Alumnas "Amalia Solórzano de Cárdenas", FECSM, CJM, UIE, FMJC, Cañada Honda, Ags, 24 de octubre de 1963. 
del acta de acuerdos el día 28 del mismo mes. ${ }^{35}$ En este proceso las peticiones de los estudiantes y las respuestas de las autoridades dejaron al descubierto varias situaciones problemáticas: la vulnerabilidad y las condiciones de pobreza de las escuelas, la existencia de prácticas administrativas ineficaces y actos de corrupción. Al mismo tiempo, quedaba demostrado que sólo a partir de la exigencia estudiantil era como las autoridades respondían. El poder de autogobierno de los estudiantes era fuerte y se había creado con los años, tal como ocurrió en la Escuela de San Marcos, Zacatecas, donde los "estudiantes se movían entre el respeto a la norma y los límites de la transgresión" (Hernández, 2016: 235-236).

En las negociaciones era clave el incremento en la partida de recreación escolar y el aumento de becas y de matrícula como condición para que los dirigentes estudiantiles dieran por concluido el conflicto. ${ }^{36}$ Así mismo, las autoridades aclaraban que lo que en ese momento no se pudiera conceder sería incluido en el presupuesto para 1964,37 en el cual también la FECSM demandaría la eliminación de cuotas de inscripción. ${ }^{38}$ Además, la organización estudiantil se pretendía fuerte por sus vínculos con la Federación Mundial de la Juventud Democrática y la Unión Internacional de Estudiantes.

\section{Frente al fantasma del normalismo rural}

El proceso de unificación de los normalistas rurales se dio en un ambiente político afectado por el fantasma del comunismo (Loaeza, 1988: 135-139)39 y las campañas políticas de los aspirantes a la presidencia de la República de 1964, entre quienes se encontraban José González Torres por el Partido Acción Nacional (PAN), Gustavo Díaz Ordaz por el Partido Revolucionario Institucional (PRI), y el profesor Ramón Danzós Palomino quien representaba a la izquierda mexicana al haber sido postulado por el Frente Electoral del Pueblo (FEP), una representación del Partido Comunista Mexicano y el Movimiento de Liberación Nacional (García, 2006: 73-115). ${ }^{40}$

${ }^{35}$ ACENRJSM, Caja 30, 1960-1964, "Conclusiones y acuerdos referentes al Pliego de peticiones presentado el 3 de octubre", SEP, 29 de octubre de 1963

${ }^{36}$ ACENRJSM, Caja 30, 1960-1964, "Conclusiones del Pliego de peticiones presentado ante la SEP, FECSM y CNECSM", 3 de octubre de 1963, hoja 4.

${ }^{37}$ AGENRJSM, Caja 30, 1960-1964, "Dando Respuesta al nuevo Pliego de peticiones", Dirección General de Enseñanza Normal, Circular No. 59, 19 y 22 de octubre y Conclusiones y acuerdos... 29 de octubre de 1963.

${ }^{38}$ AGENRJSM, Caja 30, 1960-1964, Dirección General de Enseñanza Normal, Circular No. 11, 3 de marzo de 1964.

39 "Un fantasma recorre Europa: el fantasma del comunismo...", es la primera línea con la que Marx y Engels inician el Manifiesto del Partido Comunista, cuyo objetivo es explicar el nacimiento de una nueva clase social con intereses propios: la clase obrera. (Marx y Engels, 2005).

40 En el MLN estaban Carlos Fuentes, Pablo González Casanova, Heberto Castillo, Rubén Jaramillo, Manuel Marcué Pardiñas, Genaro Vázquez Rojas y el propio general Lázaro Cárdenas. (Glockner, 2007: 114-119). 
En este contexto, la vida de estas escuelas se tornó por demás compleja, luego de que ante cualquier manifestación o intento de unificación, los normalistas fueron acusados de atentar en contra de la "estabilidad del país", al grado de mencionar que algunos de ellos planeaban asesinar al candidato presidencial del PRI, según lo cuenta José Santos Valdés (Valdés, 1982: 307). A veces se tenían espacios de negociación y entendimiento para evitar que crecieran los conflictos; por ejemplo, la Normal de Cañada Honda, Aguascalientes, a pesar de encontrarse en una situación de hostigamiento permanente, recibió "lo mismo al hombre del pueblo, general de División Lázaro Cárdenas; al hombre de paz y el trabajo, Lic. Adolfo López Mateos; al estadista, Sr. Lic. Gustavo Díaz Ordaz". ${ }^{41}$

Por otro lado, además de haber contado con la visita del inspector de normales, José Santos Valdés, los primeros días de abril de $1964^{42}$ y haber solicitado a las autoridades educativas la realización de las XII Jornadas en esta escuela, ${ }^{43}$ la Normal de Cañada Honda también se convirtió en la sede de las reuniones con representantes estudiantiles de las diferentes normales rurales, cuya finalidad era establecer los mecanismos de unificación de su organización (Valdés, 1982: 311). La prensa, por su parte, catalogó cualquier tipo de manifestación como opositora al gobierno y acusó de comunistas a los inconformes; incluso reprobó la campaña política del FEP y a su candidato, en ocasión de un acto proselitista realizado en Fresnillo, Zacatecas, y el cual fue cubierto por El Sol del Centro, un diario cuyo propietario era un empresario que había asumido dentro de su política editorial el anticomunismo:

Entre sus acompañantes se encontraba el agitador del Magisterio, profesor Othón Salazar, quien también hizo uso de la palabra [...] Danzós Palomino arribó a bordo de un automóvil Cadillac y al abordar la tribuna pronunció un discurso en que él llamo "poquiancheros" a los Presidentes Municipales. Su peroración se prolongó por unos cuarenta minutos, ante un escaso auditorio [...] Hay que hacer notar que el Frente Electoral del Pueblo no fue reconocido como partido político por la Secretaría de Gobernación en virtud de que no reúne el mínimo de requisitos que señala la ley ${ }^{44}$

41 "Discurso pronunciado por la Señorita Yolanda Romero Vázquez, alumna del sexto año Normal, en la recepción tributada al Sr. Lic. Agustín Yánez, Secretario de Educación Pública en la Escuela Normal Rural 'Justo Sierra Méndez' de Cañada Honda, Ags.", 6 de marzo de 1965. Durante estos años se tuvo la visita de Lázaro Cárdenas y, por segunda ocasión, la de Gustavo Díaz Ordaz. Caja 30, 1960-1964, "Invitación oficial para el festival de clausura de esta Escuela al C. Gral. Lázaro Cárdenas del Río", 12 de junio de 1964 y Caja 32, 1965-1967, "Discurso pronunciado por la Señorita Graciela Reyes Martínez, con motivo de la recepción que se le tributó al C. Lic. Gustavo Díaz Ordaz... en la Escuela Normal Rural 'Justo Sierra Méndez', de Cañada Honda, Ags.", 7 de febrero de 1967, respectivamente.

42 ACENRJSM, Caja 30, 1960-1964, Sección Correspondencia, Citatorio a reunión con motivo de la visita de José Santos Valdés a esta escuela", 1 de abril de 1964

${ }^{43}$ ACENRJSM, Caja 30, 1960-1964, Normal Rural Cañada Honda, Ags., Sociedad de Alumnas "Amalia Solórzano de Cárdenas", "Pide se dé Jornada próxima Deportiva y Cultural", 10 de mayo de 1964.

44 "Mitin pro Ramón Danzós Palomino en Fresnillo, ayer", El Sol del Centro, 13 abril de 1964, AHEA. 
Este diario menciona que después de haber realizado una visita al municipio de Rincón de Romos, Aguascalientes, Danzós Palomino cerró sus actividades con un mitin en la plaza principal de Aguascalientes. ${ }^{45}$ Igual que con lo ocurrido en Zacatecas la prensa volvió a mostrar su postura oficialista y su rechazo a la izquierda:

\begin{abstract}
Usando un lenguaje agresivo, a veces con insultos velados para el Presidente López Mateos y para el licenciado Gustavo Díaz Ordaz, ocho oradores ocuparon anoche la tribuna en la Plaza Principal en el mitin político del Frente Electoral del Pueblo, a favor de su candidato presidencial Ramón Danzós Palomino. Los oradores, entre ellos el profesor Othón Salazar, que alcanzó cierta notoriedad como agitador comunista del magisterio, y el propio candidato, dirigente campesino de la cCl (Central Campesina Independiente), lanzaron invectivas al PRI y a quienes gobiernan el país [...] Unas doscientas personas, mayoría curiosos, estuvieron presentes. ${ }^{46}$
\end{abstract}

El diario destacaba la participación de líderes ferrocarrileros locales y de la dirigencia nacional del gremio de filiación vallejista. ${ }^{47}$ En este mitin también estaban las normalistas de Cañada Honda, quienes apoyaban al candidato de izquierda y criticaban al oficial, tal como ocurrió en Chihuahua el 6 de abril cuando el joven Jesús Mariñelarena le exigió a Díaz Ordaz "la libertad de algunos de sus compañeros que estaban en cárceles por haber exigido reparto de tierras para los campesinos chihuahuenses" (Viramontes, 2009). Al final, ese mitin se transformó en un evento de agresiones que impidió que el candidato leyera su discurso. La prensa señalaba que los responsables del zafarrancho habían sido los normalistas. Así quedó asentado en un diario de Aguascalientes, el cual remató diciendo que "muchas de las Escuelas Normales, especialmente entre las Rurales, son nido de rojillos, y como tales, focos de dispersión de ideas disolventes y de actos de agitación". 48

Este diario también acusaba a los alumnos de San Marcos, Zacatecas, de criticar irresponsablemente a Díaz Ordaz a través de su órgano periodístico Fulgor Normalista, porque el candidato del PRI no convenía a los intereses que movían a los estudiantes. Según el diario, con los sucesos de Chihuahua quedaba demostrado que había una consigna en "estas células comunistas para agitar en contra del ex secretario de Cobernación" y poner de manifiesto que los estudiantes estaban preparados "como parte de una conjura para extorsionar las

45 "Mitin pro Ramón Danzós Palomino hoy en esta ciudad", El Sol del Centro, 17 abril de 1964, AHEA.

46 "Oradores agresivos en el mitin pro Ramón Danzós P.", El Sol del Centro, 18 abril de 1964, AHEA.

${ }^{47}$ Con la huelga de los ferrocarrileros, a partir de 1958, que seguidos por maestros y petroleros se convirtieron en la cresta de la ola que ponía en aprietos la marcha de la economía y de la política, se puede advertir la presencia de líderes como Demetrio Vallejo y Valentín Campa, antiguo militante del Partido Comunista Mexicano. El conflicto ferrocarrilero, que muy pronto se convirtió en un problema nacional, fue liderado en Aguascalientes por el vallejista Ángel Venegas Ahumada. Aguilar y Meyer, 1995.

${ }^{48}$ Columna "Zurriago Normalista", El Sol del Centro, 18 abril de 1964, AHEA. 
ideas políticas que profesa el Lic. Díaz Ordaz y que son opuestas a las que sustentan los comunistas". 49

Aunque en el fondo se trataba de evitar el involucramiento de la FECSM en estos sucesos, de acuerdo con José Santos Valdés durante el periodo comprendido entre 1960 y 1965 las autoridades hicieron todo lo necesario para convertir el tema del normalismo rural en el fantasma al que había que desaparecer..$^{50}$ Así ocurrió con los estudiantes de las escuelas de Saucillo y Salaices, en Chihuahua, que fueron perseguidos y hostigados tras haber sido acusados de agitadores comunistas que pretendían formar grupos guerrilleros y desquiciar el orden social. El problema no era menor, pues el vínculo entre normalistas y movimientos sociales, en particular el campesino, era estrecho y los brotes de rebeldía estaban a flor de piel (A. García, 2015). El propio Santos Valdés creía que había una exageración en el proceder del gobierno porque, pese a que se trataba de jóvenes cuyas edades oscilaban entre los 12 y los 18 años, éstos eran vigilados constantemente por la policía secreta del Estado, las policías estatales y municipales, "por espías de la FBI y de la CIA y, peor aún, por soldados del Ejército Nacional" (Valdés, 1982: 202-343). Ciertamente, la Guerra Fría justificaba el autoritarismo del régimen político, puesto que los controles policiacos y la propaganda de los periódicos buscaban, detrás del fantasma de un comunismo casi inexistente, apagar los liderazgos sociales más combativos en regiones y organizaciones, tales como los de Rubén Jaramillo, Demetrio Vallejo y el profesor Othón Salazar, entre otros, así como centenas de militantes de izquierda, agraristas y sindicalistas, muchos de los cuales fueron encarcelados o asesinados (Servín, 2014: 38).

En Aguascalientes, no obstante la aparente calma ante la visita del candidato Gustavo Díaz Ordaz a Cañada Honda el 10 de febrero de 1964, las estudiantes le manifestaron su preocupación por la persecución y el hostigamiento de los que venían siendo objeto, aunque también le expresaron su confianza y beneplácito porque con su visita se acortaba la distancia entre "el sufrido y mal interpretado estudiante campesino y el noble y viril intelectual de gran valía" y demostraba que el candidato deseaba percatarse de sus necesidades y problemas asistiendo a su escuela. En lo que parece una manifestación de ingenuidad estudiantil, por lo que significaría este gobierno para el normalismo rural, también le confesaron la certeza de sentirse "entre los grupos estudiantiles más revolucionarios [...], pues no podemos apartarnos ni de nuestro origen, y de la función social y ética del magisterio". ${ }^{51}$ Con este antece-

$49 / \mathrm{dem}$.

${ }^{50}$ De 1960 a 1965 estuvo como encargado de la Inspección de Enseñanza Normal en la Zona Norte, de la cual formaban parte, entre otras, las normales rurales de Cañada Honda, San Marcos y las de Durango, Sonora y Chihuahua. Sobre el trabajo de este destacado profesor véase Morales (2016).

${ }^{51}$ ACENRJSM, Caja 32, 1965-1967. "Discurso pronunciado por la Señorita Ma. Elena Lucio Ortiz del Sexto Año Normal, en la recepción que se ofreció al Lic. Gustavo Díaz Ordaz, en la Escuela Normal Rural 'Justo Sierra Méndez', de Cañada Honda, Ags.", Cañada Honda, Ags., 10 de febrero de 1964. 
dente, a mediados del mes de abril y a lo largo del mes de mayo se reunieron en esta escuela representantes de sociedades de alumnos pertenecientes a la FECSM con la finalidad de lograr su reunificación. La noticia corrió rápido y surgió la versión de que se juntaban a conspirar en contra del gobierno: "[Corrió] la versión de que los líderes de los estudiantes normalistas rurales, reunidos en Cañada Honda, Ags., trataban de organizar y —desde luego llevar a cabo - un movimiento armado en todo el país y que para iniciarlo, para abrir boca —como quien dice-, el $1^{\circ}$ de mayo, aprovechando el desfile obrero en la ciudad de Aguascalientes, provocarían un motín sangriento" (Valdés, 1982: 311).

Coincidentemente, en un hecho que concuerda con la hipótesis de la persecución y el hostigamiento de los que venían siendo objeto estas escuelas, en un oficio dirigido al procurador general de Justicia de Aguascalientes el director de la escuela le informaba que desde las últimas semanas de febrero y los primeros días de marzo habían empezado a darse "algunos hechos fuera de lo normal [...] dentro del perímetro de esta institución". Y señalaba: "con mucha frecuencia transita por los linderos de la Escuela un vehículo no identificado sin placas, color negro, a altas horas de la noche". 52

En el desfile del $I^{\circ}$ de mayo no sucedió lo que se había previsto, aunque sí hubo expresiones de apoyo a los ferrocarrileros disidentes encabezados por Demetrio Vallejo. Según las autoridades, en la ciudad de Aguascalientes un "grupo de normalistas rurales de San Marcos -con su banda de guerra- había desfilado a la cabeza de los obreros ferrocarrileros vallejistas", lo que desde su punto de vista significaba una seria alteración del orden social. Y la zozobra continuó. Más tarde sucedió con los normalistas de Roque, Guanajuato, a quienes se les acusó de preparar un levantamiento armado para julio, el día de las elecciones presidenciales (Valdés, 1982: 202-343).

La idea de que estas escuelas eran bastiones de comunistas fortaleció la tendencia de cerrar algunas de ellas por lo que los estudiantes no cesaron en su empeño de favorecer la unificación de su organización, ${ }^{53}$ pues muchos no dudaban de que al llegar a la presidencia de la República Gustavo Díaz Ordaz "hiciera pedazos a las Normales Rurales" (Valdés, 1982: 313). Así, con el apoyo de los consejos de la FECSM, que eran espacios "orientados hacia la realización de acciones que permitieran adquirir una conciencia unitaria, nacional e internacional", entre abril y mayo de 1964 los representantes de todas las normales rurales se reu-

52 Oficio dirigido al Lic. Manuel Ávila Salado, titular de la pgr en el Estado en el que "Se ponen en conocimiento anomalías que acontecen por las noches en la Escuela". Silverio Díaz Cárdenas, director de la Escuela Normal Rural de Cañada Honda. ACEnRJsm, Caja 30, 1960-1964, Sección Correspondencia, Oficio núm. 328, 12 de marzo de 1964.

${ }_{53}$ Se anunciaba la presencia de representantes estudiantiles de las normales rurales de San Marcos, Zac.; Panotla, Tlax.; Palmira, Mor.; Santa Teresa, Coah.; Saucillo, Chih.; Salaices, Chih.; J. Guadalupe Aguilera, Dgo.; Roque, Gto.; El Mexe, Hgo.; Jalisco, Nay:; Ayotzinapa, Gro.; y Cañada Honda, Ags. "Congreso Nacional de Normalistas Rurales en Cañada Honda", El Sol del Centro, 19 de mayo de 1964, AHEA. 
nieron para concretar la unidad de su organización nacional (Federación de Estudiantes Campesinos Socialistas de México, 2005-2006: 8).

Junto a la reunificación y las demandas de mejorar la infraestructura, otro propósito de los estudiantes fue analizar críticamente su formación como docentes, por lo que el temario del congreso consideró los siguientes tópicos: 1. Examen de los problemas generales del alumnado; 2. Análisis sobre la forma en que están funcionando las escuelas normales rurales; y 3. La contribución de los maestros a las mejores causas de México. ${ }^{54} \mathrm{El}$ Congreso de Unidad finalmente tuvo lugar en el mes de noviembre en la misma escuela de Cañada Honda. ${ }^{55}$ En esa ocasión y con la participación de 27 de las 29 escuelas que para entonces existían, los normalistas rurales salieron unificados y fortalecidos el 7 de noviembre de ese año. ${ }^{56}$

Dado que se trató de un acontecimiento que siguió un proceso de varios meses, los normalistas rurales no sólo valoraron la importancia de este tipo de escuelas para la expansión y mejora del sistema educativo en México, sino que a través de los consejos de la FECSM, desarrollados desde el mes de abril de ese año, también orientaron las acciones para adquirir "una conciencia unitaria nacional e internacional" (Federación de Estudiantes Campesinos Socialistas de México, 2005-2006: 8) y definir las condiciones de unificación de su organización estudiantil. En este sentido el movimiento estudiantil planteaba propuestas ambiciosas que no sólo tenían que ver con la unidad sino con la mejora de su formación como futuros docentes y, por si fuera poco, con una labor social que contribuyera "a las mejores causas de México".

\section{Consideraciones finales}

En 1964 las dos facciones existentes del normalismo rural mexicano se vieron en la necesidad de fortalecer su unidad y dejar de lado sus diferencias para hacer frente a los embates del gobierno federal, que pretendía acallar y controlar las iniciativas de los estudiantes. La realización del Congreso de la Unidad del Normalismo Rural finalmente ayudó a que las sociedades de alumnos fortalecieran su presencia política y social mediante la realización de paros y huelgas congruentes con las disposiciones de la FECSM, ${ }^{57}$ y a valorar la importancia de

\footnotetext{
54 "Exponen el Temario de su Congreso los Estudiantes Normalistas Rurales", El Sol del Centro, 20 de mayo de 1964, AHEA.

${ }^{55}$ ACENRJSM, Caja 31, 1963-1966, Dirección General de Enseñanza Normal, Telegrama núm. 9845 para informar los días de realización del Congreso y de la Normal Rural de Zaragoza, Puebla Telegrama No. 117.

${ }^{56}$ Entrevista de Sergio Ortiz Briano a Élida Hernández González, Pabellón de Arteaga, Ags., 8 de septiembre de 2007.

57 ACEnRJSM, Caja 30, 1960-1964, Sociedad de Alumnas "Amalia Solórzano de Cárdenas", oficio dirigido al director del plantel "Dando a conocer acuerdo del Comité Nacional de la FECSM" en apoyo a los normalistas rurales de Chihuahua, 16 de noviembre de 1964; luego de tres paros de actividades convocados por la FECSM de 12, 24 y 48 horas, respectivamente, los estudiantes anuncian "la suspensión total de actividades en nuestra institución (huelga) cuyos
} 
continuar manifestando sus demandas conjuntamente para beneficio de sus escuelas. Sin embargo, al igual que en otros momentos, en la segunda mitad de los años sesenta sus demandas fueron desatendidas, lo que dio pie a que hubiera nuevas manifestaciones, como ocurrió en los primeros meses de $1968,{ }^{58}$ al grado de exacerbar ánimos y propiciar la unidad con el movimiento estudiantil universitario (Guevara, 2004: 97).

La realización del XXXII Congreso Nacional de la FECSM en Cañada Honda en noviembre de 1968 fue un intento gubernamental por debilitar el movimiento estudiantil, pero también la oportunidad de negociar y favorecer la unidad del normalismo rural mexicano. En octubre se realizaron paros de actividades en todas las normales rurales del país, argumentando el incumplimiento del convenio que había dado fin a la pasada huelga ${ }^{59}$ y protestando por lo ocurrido el día 2 de ese mismo mes. Fue hasta el 7 de noviembre cuando la dirigencia nacional de la FECSM dio a conocer a las autoridades su decisión de suspender labores. ${ }^{60}$

En una actitud poco común del gobierno, pero que dejaba ver su interés por desestabilizar nuevamente la unidad estudiantil, las demandas de la escuela sede fueron resueltas en muy poco tiempo. El gobernador de Aguascalientes, Enrique Olivares Santana, les arrebataba la bandera de apoyo al resto de los normalistas rurales al dejarlos sin argumentos frente a la posibilidad de una huelga. "También aquí, bajita la mano [Olivares Santana] platicaba con las del Comité Ejecutivo." ${ }^{11}$ Aun así los problemas continuaron porque las carencias en las escuelas no eran pocas y porque a finales de 1968 los estudiantes empezaron a mostrar oposición a la reforma de las normales, la cual se concretó en 1969 y concluyó con el cierre

motivos son obvios de mencionarse"; ACENRJSM, Caja 31, 1963-1966, Sociedad de Alumnas "Amalia Solórzano de Cárdenas", "Informando la realización de un paro de 12 horas que se está llevando a cabo el día de hoy, 26 de marzo de 1965; Se comunica la suspensión de clases por un paro de 24 horas, de las 6 de la mañana del día 29 a las 6 de la mañana del día 30, 29 de marzo de 1965; Para hacer de su conocimiento la realización de un tercer paro, ahora de 48 horas consecutivas", 30 de marzo de 1965; y "Se anuncia la suspensión de actividades por huelga", 1 de abril de 1965; ACENRJSM, Caja 31, 1963-1966, Sociedad de Alumnas "Amalia Solórzano de Cárdenas", Oficio "Para hacer de su conocimiento la terminación legal de la Huelga que tuvo duración de 23 días", 24 de abril de 1965; y AGENRSMz, aja 12, 1966-1967, Sociedad de Alumnos "Lázaro Cárdenas" de San Marcos, Zac., "Oficio de Identificación de alumnos integrantes del club de Orientación Política e Ideológica que apoyarán en las guardias que se realizan con motivo del movimiento de las Normales Rurales", abril de 1965.

${ }^{58}$ AGEnRJSM, Caja 33, 1966-1969, Sociedad de Alumnas "Amalia Solórzano de Cárdenas", Circular, Secretaría General, "Comunicando realización de paro de actividades de 48 horas", 18 de febrero de 1968; y Prof. Francisco Díaz Cárdenas, director de la Escuela Normal de Cañada Honda, Ags., Telegrama Oficial núm. 116, "Infórmole con esta fecha Paro Duración Setenta y Dos Horas", 22 de febrero de 1968.

${ }^{59}$ ACENRJSM, Caja 34, 1968-1970, Dirección General de Enseñanza Normal, Oficio 10434, al "Comité Ejecutivo de la Federación de Estudiantes Campesinos Socialistas de México", 4 de octubre de 1968.

60 AGENRJSM, Caja 34, 1968-1970, Dirección General de Enseñanza Normal, Oficio 12656, "A los padres de familia y estudiantes de la Sociedad de Alumnas de la Escuela Normal Rural de Cañada Honda, Ags.", 18 de noviembre de 1968.

${ }^{61}$ Entrevista de Sergio Ortiz Briano a Élida Hernández González, Pabellón de Arteaga, Ags., 8 de septiembre del 2007. Élida Hernández González fungió como titular en la Secretaría de Actas y Acuerdos del Comité Ejecutivo de la Sociedad de Alumnas "Amalia Solórzano de Cárdenas". 
de 14 planteles. La problemática de las normales rurales también coincidía con la crisis que venían enfrentando las universidades públicas del país durante los años sesenta, misma que desembocó en la matanza del 2 de octubre en la Ciudad de México.

En 1969, no obstante que la SEP había anunciado un incremento en la matrícula en escuelas normales y había abierto una normal para mujeres en Quintana Roo, tras la realización del IV Congreso de Educación Normal de Saltillo, se dio a conocer un importante cambio: "separar el ciclo secundario del profesional, congregando a todos los estudiantes de secundaria en escuelas técnicas agropecuarias y a todos los que cursan estudios profesionales en escuelas normales". 62 De esta manera y contradiciendo lo señalado por el propio Agustín Yánez apenas tres meses antes, se había iniciado el proceso de cierre de 14 normales rurales en el país. Al mismo tiempo, "en 1969 Díaz Ordaz ordenó la ocupación de algunas normales rurales para desarticular a la FECSM y a la Central Nacional de Estudiantes Democráticos" (Castellanos, 2008: 172).

En suma, las circunstancias que envolvieron al normalismo rural a lo largo de este periodo permiten identificar las estrategias que desarrollaron los estudiantes para obtener respuesta de las autoridades de gobierno en atención a sus necesidades, pero también los mecanismos de control tanto de estas autoridades como de la dirigencia del SNTE. En cualquier caso, junto con el protagonismo de la normal rural de Cañada Honda en momentos coyunturales, también se advierte la preocupación del gobierno mexicano frente a la posibilidad de que se propagaran las expresiones de inconformidad estudiantil en otros sectores de la población y, finalmente, la decisión de eliminar las luchas estudiantiles a partir del cierre y reorganización de las escuelas normales rurales.

Se advierte también, a través de estos procesos, que en los momentos en que la autoridad ha decidido tomar medidas encaminadas a replantear la formación de maestros, particularmente de maestros rurales, le ha sido suficiente con crear argumentos que justifican sus decisiones. Así, en el periodo al que nos referimos, bastó con que la autoridad justificara la separación del ciclo secundario del normal y el cierre de las 14 normales rurales, argumentando que en estas escuelas se habían tenido "graves problemas de la promiscuidad de niños de 12 y 13 años de edad con jóvenes de 18, 20 y más años [...] siempre en perjuicio y con grave daño físico y moral para los de menor edad" ${ }^{63}$

${ }^{62}$ AGENRJSM, Caja 34, 1968-1970, SEP, DGEN, "La Reforma de la Enseñanza Normal”. Discurso del Prof. Ramón G. Bonfil, pronunciado en la inauguración de la reunión de directores, subdirectores y profesores de planta de las escuelas normales del país, 18 de agosto de 1969, hoja 1. Mario Aguilera Dorantes, oficial mayor de la SEP anunció dicha transformación el 22 de julio de 1969. José Enrique Pérez, Cuadernos de Educación Sindical núm. 90, Las luchas estudiantiles en México, disponible en http://www.stunam.org.mx/8prensa/cuadernillos/cuaderno90-5.html (consultada el 3 de febrero de 2008).

${ }^{63}$ ACENRJSM, Caja 34, 1968-1970, SEP, DGEN, "La Reforma de la Enseñanza Normal". Discurso del Prof. Ramón G. Bonfil pronunciado en la inauguración de la reunión de directores, subdirectores y profesores de planta de las escuelas normales del país, 18 de agosto de 1969, hoja 2. 
De esta manera, a pesar de la cultura de intercambio y fraternidad construida a través de muchos años, con el cambio de estudiantes de unas escuelas a otras distantes las sociedades de alumnos quedaron desarticuladas, incapaces de intentar siquiera luchar por revertir esta determinación. Por mencionar un dato, de acuerdo con información presentada por Ramón G. Bonfil en agosto de 1969, más de 10000 alumnos debieron ser removidos de su lugar. De esta manera, aunque en algunas normales rurales hubo disturbios durante los meses de septiembre y octubre en protesta contra la reforma ${ }^{64}$ en otras, como la de Cañada Honda, las actividades continuaron desarrollándose de manera normal.65 Terminó el año 1969 y también concluía un ciclo en la vida de la FECSM, pero ésta no desapareció.

Al iniciar los años setenta algunos estudiantes decidieron tomar las armas y ser guerrilleros ante la cerrazón gubernamental para atender asuntos de justicia social y participación democrática. Los grupos guerrilleros encabezados por Lucio Cabañas, egresado de la normal rural de Ayotzinapa, y Genaro Vázquez, entre otras organizaciones radicalizadas, fueron víctimas de lo que más tarde se llamó la "guerra sucia" porque fue la embestida violenta de los representantes del Estado contra "la razón de ser de las instituciones", contra los derechos humanos y contra de las constantes exigencias ciudadanas (Scherer y Monsiváis, 2004: 199).

Desde la subalternidad los normalistas rurales aún siguen sosteniendo una ideología justiciera y el propósito que se reiteró en el III Congreso de la FECSM en 1937 de formar profesores con "la conciencia de su noble misión, para que actúen allí como transformadores del medio rural de México" ${ }^{66}$

A raíz de la desaparición de los 43 normalistas de Ayotzinapa el espíritu de lucha sigue porque, como señaló una egresada de la normal de Cañada Honda, aún se tiene una ideología que responde al "espíritu revolucionario del que nos hemos nutrido en estas escuelas [y que todavía] debe ser la llama que dirija nuestras vidas como profesores y como ciudadanos rebeldes del mundo" ${ }^{67}$

Tanalís Padilla rescata la importancia de la lucha de estos normalistas en la actualidad, la cual se explica a partir precisamente de su historia:

Una de las características más llamativas de la historia de las normales rurales es el aire esperanzador con que sus alumnos describen su estancia allí. La posibilidad de

\footnotetext{
${ }^{64}$ AGENRJSM, Caja 35, 1969-1971, SEP DCEn, Comunicado de Ramón G. Bonfil, "A los padres de familia", 28 de noviembre de 1969

${ }^{65}$ AGENRJSM, Caja 35, 1969-1971, Normal Rural de Cañada Honda, Ags. Telegrama Oficial 04 dirigido a Ramón G. Bonfil, "Escuela continúa con actividades normales", 8 de septiembre de 1969.

${ }^{66}$ Surco, 20 de noviembre de 1937, pp. 2 y 4

${ }^{67}$ Amelia Castillo, egresada de Cañada Honda de la generación 1978-1982, en un mensaje dirigido a las estudiantes de esta escuela en 1994. Citado en "Cañada Honda: la convicción del normalismo rural", en Luis Hernández Navarro, La Jornada, secc. Opinión, 8 de junio del 2010. <http://www.jornada.unam.mx/2010/06/08/opinion/02lalpol>. Consultada el 12 de junio de 2010.
} 
estudiar, vivir en colectivo, las excursiones, encuentros deportivos y culturales, y la explicación que su estudio y activismo da al por qué de la pobreza, hacen de estas instituciones experiencias de vida formativas. Las normales rurales son el camino hacia una profesión digna y, a veces, otorgan, despiertan y cultivan el derecho a soñar.

Desde el poder, se pinta otra historia: una en la cual las normales rurales son reliquias del pasado, centros de agitación y espacios de ocio juvenil. Las demandas que hacen los alumnos para el mejoramiento estructural de las normales son vistas con agrio desprecio. ¿Con qué derecho estos chavos plebe se atreven a exigir un lugar privilegiado en el país?, es la implícita pregunta de la mayoría de los medios masivos cuya visión hace eco de los que detentan el poder. ${ }^{68}$

\section{Fuentes}

Archivos consultados

AGENRNJSM Archivo General de la Escuela Normal Rural "Justo Sierra Méndez", Aguascalientes.

AGN Archivo General de la Nación, Ciudad de México.

AHEA Archivo Histórico del Estado de Aguascalientes, Aguascalientes.

AHSEP Archivo Histórico de la Secretaría de Educación, Ciudad de México.

HPUUM Hemeroteca Pública Universitaria "Mariano de Jesús Torres", Universidad Michoacana de San Nicolás de Hidalgo, Morelia, Michoacán.

Fuentes hemerográficas

Diario de Yucatán. Yucatán.com.mx (s/f), "Detienen en Michoacán a 52 estudiantes normalistas", Diario de Yucatán. Yucatán.com.mx, disponible en <http://yucatan.com.mx/mexico/delincuencia/detienenen-michoacan-a-52-estudiantes-normalistas> (consultada el 9 de diciembre de 2015).

La Jornada, Ciudad de México, <http://www.jornada.unam.mx>

Surco (1937), Órgano quincenal de información y doctrina, núm. 12, Morelia, Michoacán, México

\section{Bibliográficas}

Acevedo, Álvaro y Gabriel Samacá (2011), "El movimiento estudiantil como objeto de estudio en la historiografía colombiana y continental: notas para un balance y una agenda de investigación", Historia y memoria, núm. 13, Universidad Industrial de Santander, Colombia, pp. 45-78.

Aguayo Álvarez, José Luis (2002), Escuela Normal Rural SALAICES Formadora de maestros, México.

Aguilar, Héctor y Lorenzo Meyer (1995), "El milagro mexicano. 1940-1968", A la sombra de la Revolución mexicana, Cal y Arena, México.

Camacho, Salvador y Yolanda Padilla (2002), Vaivenes de utopía. Historia de la educación en Aguascalientes en el siglo Xx, 2 t., IEA, México.

Camacho, Salvador (1997), "Política y desarrollo económico en México, 1940-1994: del milagro mexicano a la nueva crisis", Historias latinoamericanas. Reflexiones desde la otra América, ICA, México, pp. 247-278.

${ }^{68}$ Véase La Jornada, secc. Opinión, 4 de octubre de 2014, en: <http://www.jornada.unam.mx/2014/10/04/ opinion/Ollalpol>. 
Cardiel, Raúl (1982), "El periodo de conciliación y consolidación. 1946-1958", en Fernando Solana et al., Historia de la educación pública en México, SEP-FCE, México, pp. 327-359.

Castellanos, Laura (2008), México armado, 1943-1981, Era, México.

Castillo, Gustavo (2015), "Los 43 normalistas fueron incinerados en Cocula, ratifica la PCR", La Jornada Zacatecas, documento html disponible en: <http://jz.mx/2015/01/27/los-43-normalistas-fueronincinerados-en-cocula-ratifica-la-pgr/> (fecha de consulta: 27/01/2015).

Civera, Alicia (2013), La escuela como opción de vida. La formación de maestros normalistas rurales en México. 1921-1945, El Colegio Mexiquense, Fondo Editorial Estado de México-CEM, México.

Chabat, Jorge (2005), "Narcotráfico y Estado: El discreto encanto de la corrupción", Letras Libres, 30 de septiembre, documento html disponible en: <http://www.letraslibres.com/mexico/narcotrafico-y-estado-el-discreto-encanto-la-corrupcion> (fecha de consulta: 10/03/2017).

FECSM (Federación de Estudiantes Campesinos Socialistas de México) (2005-2006), Las normales rurales a través de la historia, FECSM. COPIN, Escuela Normal Rural Ayotzinapa, Guerrero, México.

García, Aleida (2015), La revolución que llegaría. Experiencias de solidaridad y redes de maestros y normalistas en el movimiento campesino y la guerrilla moderna en Chihuahua, 1960-1968, Colectivo Memorias Subalternas, México.

García, Daniel Carlos (2006), Fulgor rebelde. La guerrilla en Aguascalientes, Filo de Agua, ICA, México.

Glockner, Fritz (2007), Memoria roja. Historia de la guerrilla en México (1943-1968), Ediciones BSA, México.

Guevara, Gilberto (2004), La libertad nunca se olvida. Memoria del 68, Cal y Arena, México.

Hernández, Marcelo (2015), Tiempos de reforma. Estudiantes, profesores y autoridades de la Escuela Normal Rural de San Marcos frente a las reformas educativas, 1926-1984, UAZ-IPN-Zezen Baltza Editores, México.

Loaeza, Soledad (1988), Clases medias y política en México: La querella escolar, 1959-1963, El Colegio de México, México.

Marsiske, Renate (coord.) (1999), Movimientos estudiantiles en la historia de América Latina, 2 t., CESU/ unAM-Plaza y Valdés, México.

Marx, Carlos y Federico Engels (2005), Manifiesto del Partido Comunista, Ediciones Paradigmas y Utopías, PT, México.

Meyer, Lorenzo (2004), "La guerra fría en el mundo periférico: el caso del régimen autoritario mexicano. La utilidad del anticomunismo discreto", en Daniela Spenser (coord.), Espejos de la guerra fría. México, América Central y el Caribe, CIESAS-Miguel Ángel Porrúa, México, pp. 95-117.

Morales, Hallier Arnulfo (2016), La semilla en el surco. José Santos Valdés y la escuela rural mexicana, 1922-1990, tesis de doctorado en Historia, Universidad Autónoma de Zacatecas, México.

Padilla, Tanalís (2014), "La criminalización de los normalistas rurales", La Jornada, secc. Opinión, 4 de octubre, documento html disponible en: <http://www.jornada.unam.mx/2014/10/04/ opinion/01lalpol>, (fecha de consulta: 1/10/2016).

(2009), "Las normales rurales: historia y proyecto de nación", El Cotidiano, núm. 154, marzo-abril, UAM-A, México, pp. 85-93.

Padilla, Tanalís (2014), "La criminalización de los normalistas rurales", La Jornada, secc. Opinión, 4 de octubre, documento html disponible en: <http://www.jornada.unam.mx/2014/10/04/ opinion/01lalpol> (fecha de consulta: 14/01/2016).

Padilla, Yolanda y Salvador Camacho (2002), Vaivenes de utopía. Historia de la educación en Aguascalientes en el siglo XX, 2 t., IEA, México.

Pellicer de Brody, Olga y José Luis Reyna (1978), El afianzamiento de la estabilidad política, en Daniel Cosío, Villegas (dir), Luis Ganzález y González (coord.), Historia de la revolución mexicana, t. VIII. Periodo 1952-1960, vol. 22, El Colegio de México, México. 
Pérez, José Enrique (2008), "Las luchas estudiantiles en México", en Cuadernos de Educación Sindical, núm. 90, documento html disponible en: <http://www.stunam.org.mx/8prensa/cuadernillos/cuaderno90-5.html> (fecha de consulta: 3/02/2016).

Poder Ejecutivo Federal (1941), "Enseñanza agrícola" y "Los lineamientos del Plan Sexenal y el Artículo $3^{\circ}$ Constitucional", La Educación Pública en México. $1^{\circ}$ de diciembre de 1934 a 30 de noviembre de 1940, t. I, PEF, México.

Scherer, Julio y Carlos Monsiváis (2004), Los patriotas. De Tlatelolco a la guerra sucia, Aguilar, México.

Servín, Elisa (2004), "Propaganda y Guerra Fría: la campaña anticomunista en la prensa mexicana del medio siglo", Signos Históricos, núm. 11, enero-junio, pp. 9-39, documento pdf disponible en: <http:// www.redalyc.org/articulo.oa?id=34401101> (fecha de consulta: 3/02/2017).

Terán, Evangelina (2009), Del internado a la marcha. Rutinas y participación política de las alumnas de la Normal Rural "Justo Sierra Méndez" de Cañada Honda, Ags., 1939-2009, tesis de doctorado en Historia, Universidad Autónoma de Zacatecas, México.

Valdés, José Santos (1982), "Madera", en Profr. José Santos Valdés. Centenario de su natalicio 1905-2005, obras completas, t. II, Educadores Democráticos de San Marcos, Zacatecas, México.

Vaughan, Mary Kay (2000), La politica cultural en la revolución. Maestros, campesinos y escuelas en México. 1930-1940, SEP-FCE, México.

Viramontes, Óscar (2009), "Un incidente que hizo temblar a Chihuahua", Crónicas Urbanas. El Heraldo de Chihuahua, 12 de octubre, documento html disponible en: <http://www.oem.com.mx/elheraldodechihuahua/notas/n1360455.htm> (fecha de consulta: 3/11/2017).

Sercio Ortiz Briano es profesor de la Escuela Normal Rural "Justo Sierra Méndez", Cañada Honda, Aguascalientes. Doctor en Historia por la Universidad Autónoma de Zacatecas. Sus líneas de investigación son: normalismo rural y maestros rurales en México. Sus publicaciones recientes son: "Superando Barreras. La Educación Pública en el Aguascalientes Posrevolucionario, 1912-1926", en Mariana Terán et al. (coords.), Al disparo de un cañón. En torno a la batalla de Zacatecas de 1914: el tiempo, la sociedad, las instituciones, Zezen Baltza y UAz, México, 2015, pp. 581-604; Entre la nostalgia y la incertidumbre. Movimiento estudiantil en el normalismo rural mexicano, UAz, México, 2012.

Salvador Camacho Sandoval es profesor de la Universidad Autónoma de Aguascalientes. Doctor en Historia de América Latina por la Universidad de Illinois. Sus líneas de investigación son: historia de la educación en el siglo xx, política educativa y educación media y superior en México. Entre sus publicaciones recientes están: La luz y el caracol. Estudio, lucha y placer en la universidad, UAA, México, 2016; y "Política educativa, maestros y derroteros de los libros de texto en España y México, 1930-1960", Revista Mexicana de Investigación Educativa, vol. 14, núm. 39, 2009, pp. 375-401.

Recibido: 4 de abril de 2017.

Aceptado: 7 de agosto de 2017. 